\title{
MYOPERICYTOMA OF THE TONGUE: A CASE REPORT
}

\author{
Sevtap Akbulut', Derya Berk', Mehmet G Demir', Sibel Kayahan' \\ Dr. Lutfi Kirdar Kartal Training and Research Hospital, Istanbul, Turkey: Department of Otolaryngology Head and Neck \\ Surgery ${ }^{1}$, Department of Pathology ${ }^{2}$ \\ Summary: Myopericytoma is a rare benign tumour composed of pericytic cells that show myoid differentiation and have a \\ tendency for concentric perivascular growth. It belongs to a spectrum of perivascular myoid cell neoplasms. To date, only a \\ small number of cases of myopericytoma involving the oral cavity have been reported. We describe a case of myopericyto- \\ ma presenting as a slowly growing tongue nodule in a 61-year-old woman. A diagnosis of myopericytoma was established \\ with the histopathological findings combined with immunohistochemical staining. Myopericytoma should be included in \\ the differential diagnosis of well-circumscribed, slow-growing lesions of the oral cavity.
}

Key words: Myopericytoma; Tongue; Oral cavity; Histopathology

\section{Introduction}

Myopericytoma is a benign mesencyhmal tumor of pericytic cells demonstrating myoid differentiation (1). Myopericytoma is composed of oval to spindle-shaped myoid-appearing cells with a con to extend the myringotomy patency centric perivascular growth (2). It mostly arises within the skin and subcutaneous tissues of extremities (3). Myopericytoma of the oral cavity is extremely rare, only several cases have been reported in the literature $(2,4-7)$. To the best of our knowledge, there is only two reported cases of myopericytoma localized to the tongue $(4,5)$.

\section{Case History}

A 61-year old woman complained of a slow-growing, painless tongue nodule that had been present for more than a year. Clinical examination revealed 2-cm well-circumscribed firm nodule on the left mid-lateral tongue. The patient's past medical history was unremarkable. She had been using dental prosthesis for the last 10 years. On MRI there were low signal intensities on $T_{1}$ weighted images and high signal intensities on $\mathrm{T}_{2}$ weighted images. After the administration of contrast material, the lesion showed homogenous contrast enhancement and invasion of tongue muscles. An excisional biopsy of the nodule was performed for microscopic examination.

\section{Histopathologic Findings}

Microscopic examination of hematoxylin-eosin-stained sections revealed a circumscribed benign neoplasm characterized by the presence of cells arranged in concentric islands. The single-walled endothelium-lined vessels were surrounded by a concentric arrangement of myoid-appearing oval-to-spindle cells presenting bland nuclei with eosinophilic cytoplasm (Fig. 1).

Immunohistochemically, the perivascular cells were positive for smooth muscle actin, but negative for desmin and S-100 (Fig. 2). No reactivity for CD34 was evident. The Ki-67 labeling was 5\%.

After correlating the immunohistochemical pattern with the histopathological findings a diagnosis of myopericytoma was rendered. No further treatment was necessary as the lesion was totally excised, and 18 months later, there was no evidence of recurrence.

\section{Discussion}

Myopericytes are employed as cells of uncertain position in the morphologic spectrum between pericytes and vascular smooth muscle cells, and share many features with myofibroblasts (1, 7-9). Myopericytoma belongs to a spectrum of disease entity called as perivascular myoid cell neoplasm. The spectrum includes myopericytoma, solitary myofibroma, infantile-type myofibromatosis in adults, glomangiopericytoma, angioleiomyoma and glomangiomyoma (1).

Myopericytoma is known for tumors derived from, or differentiating along myopericytes (9). The defining histologic feature of myopericytoma is a distinctive, concentric perivascular proliferation of myoid tumor cells. These cells are characteristically reactive for smooth muscle actin and negative for CD34, cytokeratin and S100 protein. Vimentin and desmin are usually negative, or only focally positive, in the myopericytoma, which helps to distinguish it from other perivascular myoid neoplasms $(1,7,8)$.

Myopericytoma presents as slow-growing, well-circumscribed nodule with less than $2 \mathrm{~cm}$ in size. It most frequently affects the skin and superficial soft tissues of the distal extremities in adults; but with increased recognition, lesions in 


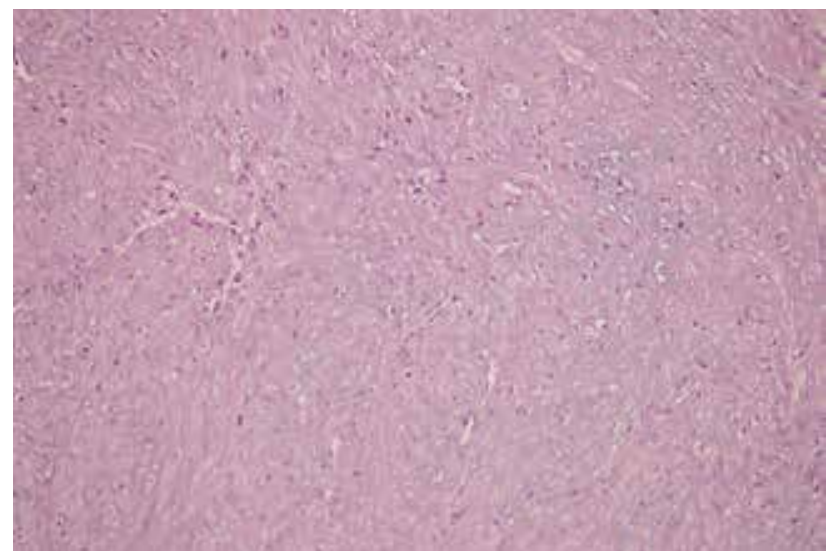

Fig. 1: Endothelium-lined, single-walled vessels, with concentric perivascular arrangement of neoplastic cells (Hematoxylin-eosin stain, original magnification $\times 20$ )

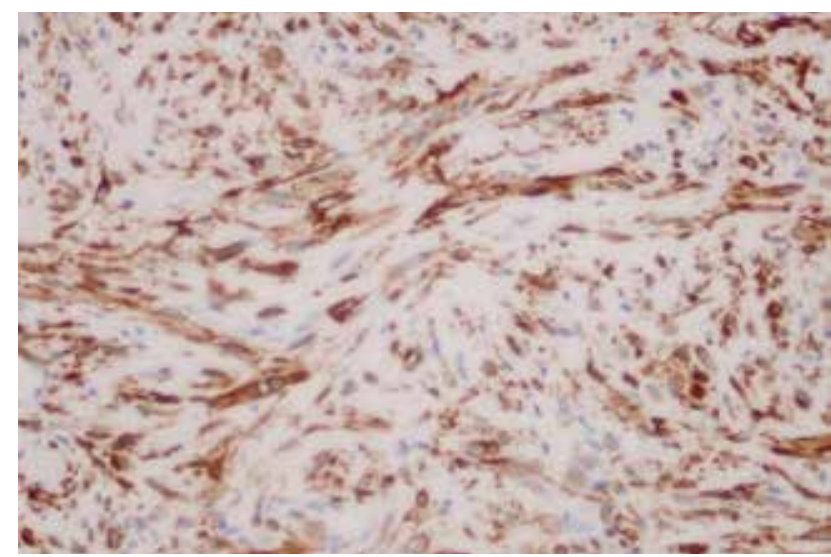

Fig. 2: The perivascular myoepithelial cells are positive for smooth muscle actin (Immunostaining, original magnification $\times 40$ )

head and neck region and trunk have been described $(3,7)$.

There are very few oral lesions reported. The very first case of myopericytoma involving the oral cavity was described by Datta et al. as a nodule on the tongue (4). Afterwards Lau et al. reported two cases with myopericytoma occurred in patients with HIV infection, among which one presented with a tongue mass (5). Sapelli et al. reported a case of myopericytoma originated from the lip (6).

Ide et al. described a rare intravascular type of myopericytoma presenting as a mass in buccal mucosa (2). After a clinicopathologic re-evaluation of 35 perivascular myoid tumors, Ide et al. revised the pathologic diagnosis as myo-

\section{Corresponding Author:}

Sevtap Akbulut, M.D., Dr. Lutfi Kirdar Kartal Egitim ve Arastirma Hastanesi KBB Bolumu, Denizer Cd., E-5 Karayolu Cevizli Mevki, 34890, Cevizli, Istanbul, Turkey; e-mail: sevtap.akbulut@gmail.com pericytoma in 2 more cases involving the lips which were originally diagnosed as angioleiomyoma. They suspected that more intra-oral myopericytoma could be found in the literature under the diagnosis of angioleiomyoma $(7,10)$. Because of morphologic similarity between myopericytoma and other perivascular myoid neoplasms, it was supposed that myopericytoma might be under-recognized by surgical pathologists.

Most cases of myopericytoma behave in a benign fashion, although a few malignant and/or recurring cases were described $(6,9)$. In the oral cavity only a case of myopericytoma of low grade malignancy was reported (11).

\section{Conclusion}

Myopericytoma is a rare benign tumor which shares morphological features with other perivascular myoid cell neoplasms. Histologic findings should be confirmed with should be kept in mind in the differential diagnosis of nodular lesions in the oral cavity. The authors presented a rare case of myopericytoma in the tongue.

\section{Acknowledgements}

The authors wish to thank Daniel B. Magraw from Foreign Policy Institute at Johns Hopkins School of Advancement International Studies (SAIS) for his editorial assistance in preparation of this manuscript.

\section{References}

1. Granter SR, Badizadegan K, Fletcher CDM. Myofibromatosis in adults, glomangiopericytoma, and myopericytoma: A spectrum of tumors showing perivascular myoid differentiation. Am J Surg Pathol 1998; 22: 513-25.

2. Ide F, Obara K, Yamada H, Mishima K, Saito I. Intravascular myopericytoma of the oral mucosa: A rare histologic variant in an uncommon location. Virchows Arch 2007; 50: 475-7.

3. Mentzel T, Dei Tos AP, Sapi Z, Kutzner H. Myopericytoma of skin and soft tissues: Clinicopathologic and immunohistochemical study of 54 cases. Am J Surg Pathol 2006; 30: 104-13.

4. Datta V, Rawal YB, Mincer HH, Anderson MK. Myopericytoma of the oral cavity. Head Neck 2007; 29: 605-8.

5. Lau PP, Wong OK, Lui PC, et al. Myopericytoma in patients with AIDS. Am J Surg Pathol 2009; 33: 1666-1671.

6. Sapelli S, Ribas M, Martins WD, Noronha L, Gomes AP. Myopericytoma of the lip:report of case. Head Neck 2009; 31: 561-4.

7. Ide F, Mishima K, Yamada H, et al. Perivascular myoid tumors of the oral region: A clinicopathologic re-evaluation of 35 cases. J Oral Pathol Med 2008; 37: 43-9

8. Requena L, Kutzner H, Hugel H, Rutten A, Furio V. Cutaneous adult myofibroma: a vascular neoplasm. J Cutan Pathol 1996; 23: 445-57.

9. McMenamin ME, Fletcher CD. Malignant myopericytoma: expanding the spectrum of tumours with myopericytic differentiation. Histopathology 2002; 41: 450-60.

10. Brooks JK, Nikitakis NG, Goodman NJ, Levy BA. Clinicopathologic characterization of oral angioleiomyomas. Oral Surg Oral Med Oral Pathol Oral Radiol Endod 2002; 94: 21-7.

11. Terada T. Myopericytoma of low grade malignancy in the oral cavity. Rare tumors 2012; 4: 24-5.

Received: $13 / 08 / 2013$

Accepted in revised form: 19/09/2013 appropriate immunohistochemical staining. Myopericytoma 